\title{
In the Hospital: Laura Shea
}

\author{
Steven Ludwin, $\mathrm{MD}^{1 *}$, Sirisha Narayana, $\mathrm{MD}^{1}$
}

'Department of Medicine, Division of Hospital Medicine, University of California, San Francisco, San Francisco, California.

W e spoke with medical social worker Laura Shea, MSW, LICSW on her role at our tertiary care hospital. Laura's reflections on the struggles and rewards of her job may resonate with those of us who search for balance and meaning in work.

Laura, tell us about yourself. What made you want to be a social worker?

I couldn't really picture doing anything else. I got a degree in psychology and loved counseling. Social work was a natural fit because of the social justice component and the look into larger systems. I knew I had the skill set for this, and for those most marginalized, to be a supportive person for someone who doesn't have that.

I also have a family member with major mental illness and chronic suicidality who I supported for a very long time. In many ways, I was a personal social worker advocating on their behalf while growing up. I remember being in high school when they overdosed, and going to the ER in the middle of the night. The next morning, I was back at school. I was a total do-gooder-President of the student council and on top of my grades. I tried dealing with this while keeping up the appearance that everything was ok, even though it wasn't.

As I got older, there were middle-of-the-night phone calls professing suicidality which were so painful. I learned a lot about compartmentalizing and resiliency. It has given me an incredible amount of empathy for family members of patients.

I have learned that it's not always simple, and decisions aren't easy, and solutions are complicated and can feel incomplete. We often hear, "Why hasn't the family stepped in?" Well these issues are hard for families too, I know from firsthand experience.

At the end of the day, as challenging as the work is, I get something from it. I feel honored to bear witness to some of people's darkest moments and also some of the most beautiful moments - the joys of coming out the other side of their process and journey.

How much of your personal story do you reveal to your patients?

I rarely do. However, to some families that are particularly devastated, I do share some of my family story. I try to affirm their challenge and acknowledge that family and friends can't always "solve this."

We have a culture that reveres going above and beyond, however I really honor those family members who can set boundaries. Sometimes caregivers need space, that doesn't make you a bad person. It's actually brave and really hard to do. You can't give from an empty well.

Laura, tell us about your typical day.

Well, it begins with responding to e-mails. Then I meet with patients and obtain collateral to prep for multidisciplinary rounds (with physicians, RNs, case managers). I usually consult on 20-30 patients a day. In the afternoon, it varies -- maybe three patients are leaving that may need my help with things like providing substance use information or shelter resources. Typically, I'll have a few complicated long-term patients, who may have challenging family dynamics, ongoing goals of care discussions, or behavioral difficulties. These patients keep me just as busy, it's not quite as time sensitive but I have to keep chipping away at the work.

Seems like a busy day. Do you get a break at all?

When possible, I take a walk in the woods behind the hospital on my lunch break. There's a beautiful path, it's an important part of my day -- getting outside and taking a step back. I bring my pager, so I am still connected.

I used to feel like I didn't have time to take a break, and I would work through lunch. But now I find if I take a break, I am more productive the rest of the day because it makes me more mindful. It quiets me a little, gives me perspective on the stress and stressors of working in the hospital and allows me to better connect to my job and others around me.

\section{What does a successful day look like?}

Well, one involved a homeless gentleman and a search for his family. He was in his 40s, though he looked much older, and recently had been assaulted at a shelter. He presented to either the ER or was admitted to various hospitals 14 times over the past month - typically for intoxication and hypothermia. He kept saying "I just need to find my brother" though no one was taking this request too seriously. We spent a lot of time looking for his brother with the Office of Public Guardian's help, and we actually found him! The patient hadn't seen his brother in four years and as it turns out was searching for him too. The

\footnotetext{
*Address correspondence to: Steven Ludwin, MD; E-mail: Steven.Ludwin@ ucsf.edu; Telephone: 415-476-4814.
}

Additional Supporting Information may be found in the online version of this article. Received: July 28, 2018; Revised: October 12, 2018; Accepted: October 18, 2018

๑ 2019 Society of Hospital Medicine DOI 10.12788/jhm.3113 
brother thought the patient had passed away. With his brother's support, the patient is now housed, going to alcohol treatment, reunited with his family, and taking his medications. His whole life changed. So that was amazing, and a reminder of how rewarding this job can be.

\section{What is most challenging about your work?}

The biggest challenge is grappling with the limitations of the system, and discharging someone to the community when the community has limited resources for these patients.

Though it's not just the limitation of resources, some patients have been through the system so many times that as a coping mechanism and to protect themselves they do everything possible to push you away. They have walls firmly up, because of prior negative experiences with providers. I am not fazed by being yelled at, but it's hard trying to connect with someone who has learned not to let you in. These are often the patients that need the support the most, and yet I want to respect their ability to have control or to say no. It is a tough balance.

\section{What's fun about your job?}

I love meeting new people. I met a woman a few weeks ago who was talking about being a hippie in the '60s in San Francisco, and how great it was and how soft millennials are. She actually put meth in her coffee because she needed a pickme-up to clean her house. You can't make this stuff up! It's just really fascinating how people live their lives, and to have a window into their world and perspective is a privilege.

Do you take work home with you or do you disconnect?

I try to disconnect, however there are days when something sticks with you and you really worry and wonder about a patient. As I mentioned, you can't give from an empty well—so I try to acknowledge this. I find that trying to have a rich life outside of work is an important part of self-care as well. Social work is a big part of my identity but it's not entirely who I am. I focus on friends, family, travel, yoga, and things that sustain me. I can't do my job effectively if I am not taking a step back regularly.

\section{What advice do you have for other providers and for patients?}

The hospital is so overwhelming for our patients, more so than some providers realize. I could be in the room with a patient for $\mathbf{4 5}$ minutes and six different providers may come in. I try to maintain that this is the patient's bedroom I'm walking into. It's a private, and a sacred space for them. That's where they sleep. This is where they are trying to recover and grapple with what brought them into the hospital.

Laura, thank you so much for telling us about your work. Anything else you'd like to share with us?

Some days I'll go home completely exhausted and wiped out, and at first, I don't feel like I did a single solitary thing. Some of the things that I'm trying to help people work through ...it never occurred to me that someone could, for whatever reason, find themselves in such challenging situations. I don't have a magic wand to provide someone with housing or sobriety, but maybe in that moment I can begin to make a connection. When I just listen, I am beginning to build relationships - which for some patients is something they haven't had in a long time. It's in these moments of being present, without an agenda, walking with them in their challenges, that I feel most connected to the work.

\section{Thanks, Laura.}

Disclosures: All authors meet the criteria for authorship stated in the Uniform Requirements for manuscripts submitted to Biomedical Journals and none have conflicts of interest to disclose in relation to this manuscript. 